\title{
Bio-medical research; how to begin (1)
}

\section{Sarath Lekamwasam ${ }^{1}$}

\author{
Sri Lanka Journal of Diabetes, Endocrinology and Metabolism 2013; 3: 39-40
}

Research is defined in many different ways. According to the Merriam-Webster Online Dictionary, research is "a studious inquiry or examination; especially investigation or experimentation aimed at the discovery and interpretation of facts, revision of accepted theories or laws in the light of new facts, or practical application of such new or revised theories or laws” (1).

Although research can be of many forms, scientific research follows a predetermined scientific method and generates scientific information which helps to understand the nature or properties of the world. In the medical field, research is done for different purposes. For academics it is a requirement for their promotions and positions. Some do research for better remuneration. Although the validity of these objectives cannot be argued, research should be done with a good intension of better understanding of science, adding new information to the current body of knowledge and, especially for clinicians, for better patient care and clinical outcomes.

In Sri Lanka, research, however, is not an integral part of professional life of most clinicians. The commonly held myth is that research is time consuming and beyond the reach of busy clinicians. A previous study reported that many postgraduate trainees wish to learn about research and get involved in active research (2). However, in practice they do not make a positive attempt to make research an integral part of their professional life.

Although research should be an essential component of the professional life of all clinicians, successful researchers have few extra qualities. They are generally curious about things happening around them, persevering in their approach, creative and independent workers, and above all, disciplined and focused in their work.

\section{Selecting a research topic}

This is the most difficult part for many. It is not uncommon to find that many particularly juniors at the beginning of the research career waste a substantial amount of time before settling in a project. Although some have a natural instinct to select an area for research many have to get outside help. It is the duty of seniors and supervisors to advice them on current research areas and trends. For a beginner, it is often helpful to collaborate with an ongoing research project, to gather experience on how to run a research until you get your "teeth in" in the subject.

Once a specific area is selected, a comprehensive literature search should be done to assess the current understanding of the subject. This allows one to identify the gaps or lacunae in the current knowledge. A critical appraisal of current literature allows one to select an important area or topic for the research. The more important the problem, the more important your results will be. One practical approach to select a research topic would be to look for the "hot areas" in your field. One needs to make sure that these "hot topics" are not motivated by transitional changes in the society such as politics. Any significant contribution in these "hot topics" will have an immediate impact on patient care or management, and gives you recognition in the research field. Selecting a topic of this nature is not without disadvantages. It is possible that others are already working in these areas and they may find a solution earlier than you making your results less attractive.

Common internet sites used for literature search

1) Google Scholar: http://scholar.google.com/

2) Medscape: http://www.medscape.com/

3) Pubmed: http://www.pubmedcentral.nih.gov/

4) Free Medical Journals: http://www. freemedical journals.com/

5) NLM: http://www.nlm.nih.gov/database/

6) Cochrane Collaboration: http://www.cochrane.org/

7) UK Evidence-based Medicine Centre: http://www.cebm.net/

8) The Community guide: http://www. thecommunityguide. org/

Once the specific research area is identified, it is important to determine whether it is an area worth spending your time and energy. The following checklist will determine the suitability of the selected topic (3). 
1) Is it a sizable clinical or social problem in the country

2) Can it be resolved by administrative changes?

3) Can a solution be found from elsewhere?

4) Is the time available sufficient?

5) Is the funding is feasible (whether it is a research priority of major funding agencies)

6) Are resources are available in the area? (include supervisors, subjects and equipment)

7) Are there no political or social implications?

Furthermore, it is important to make sure the topic is "researchable". Although you may wish to examine certain areas in medicine, the topic may be beyond your reach and embarking on a project of this nature is not productive.

\section{The "Mechanics" of research}

Professional researchers have a properly worked out mechanics of doing research. The following basic components, however, can be helpful to those staring a research career. It is often helpful to set aside a block of uninterrupted time from your weekly schedule for research. The duration can vary, based on your other engagements and priorities. Although many researches get good ideas while they are engaged in other work, leaving a protected time from your schedule to reflect on your study is helpful. People get disappointed when their research project does not make the desired progress. It is good to remember that, often, research does not progress in a "linear" fashion or on a straight line from the problem to solution. One needs to develop a feel for, when to push your project and also when to give it a rest, until you solve the problems which hinder the progress of the project.

It is important to start with the problem and keep the solutions widely open. Also question the underlying assumptions of your problem. Try to find an innovative way of looking at the problem and do not take the same path the others have traveled. Break your research into smaller and manageable "pieces" and take them one at a time. Also keep the bigger picture in your mind and decide on the next step. These may include validation of questionnaires and instruments.

\section{Objectives of the study}

Objectives are one of the important, if not the most important, components of the study. Objectives spell out what you wish to accomplish in the study. They should be clear and unambiguous. Traditionally, objectives are divided as General (one) and Specific (several).

\section{General objective}

This reflects your problem and defines the scope of the study. A common mistake is to copy the title of the study straight to the general objective.

\section{Specific objectives}

Specific objectives address the different components or aspects of your study. They breakdown your general objective into smaller logically connected specific areas that systematically address the different aspects of the problem. Specific objectives clearly state what you plan to do in the study and provide a "road map”. In summary, they should specify exactly what you will do in each phase of your study, how, when, where and for what purpose. Clearly spelled specific objectives keep the study in focus and avoid unnecessary deviations and data collection. Limit specific objectives only to 3-5 and phrase them clearly, covering different aspects of the problem. Define them in operational terms that can be measured.

In summary, research should be a integral part of the professional career of clinicians. The motivation for research should primarily be purely to find new information to understand the science or improve patient care. The beginning of the project is the most difficult part for busy clinicians. A protected time should be left aside to engage in research and improve research skills.

This article is the first of the series of articles addressing bio-medical research. The main objective of the series is to introduce the basic concepts of research to busy clinicians hoping that one day they will positively engage in meaningful research.

\section{References}

1. www.merriam-webster.com/dictonary/research (accessed 5th Feb 2012).

2. Wanigasuriya K. Journal of the Ceylon College of Physicians 2011; 42: 16-20.

3. Amar-Singh HSS, Bakar AA, Sararaks S. The Medical Research Handbook, Planning a Research project. ISBN 978-983-422269-8-5. 